\title{
Comunicação
}

[Communication]

\section{Efeito do peso ao abate nos rendimentos dos processamentos do pacu (Piaractus mesopotamicus)}

\author{
L. Basso, M.W. Ferreira*, A.R. Silva \\ Universidade Católica Dom Bosco - UCDB \\ Av. Tamandaré, 6000 \\ 79117-900 - Campo Grande, MS
}

[Effect of body weight on processing yields of Pacu (Piaractus mesopotamicus)]

O pacu (Piaractus mesopotamicus) é originado principalmente dos rios Paraguai e Paraná, típico do Pantanal mato-grossense, dos rios amazônicos e da Bacia do Rio da Prata (Vaz et al., 2000). Segundo Carvalho e Lemos (2009), o consumo de peixes no Brasil é um dos mais baixos do mundo, representando apenas 5\% das carnes consumidas. Entre os fatores que contribuem para isso está a forma de apresentação dos peixes nativos brasileiros para comercialização, que pode limitar o consumo, principalmente devido à não padronização do produto.

Relacionado à agregação de valores está primordialmente o processamento do pescado, que é considerado fator de grande valia no mercado consumidor. Para a indústria, a qualidade da carcaça do pescado é fator imprescindível para definição dos processos de preparação dos produtos e dos tipos de cortes. $\mathrm{O}$ rendimento de filé, além da eficiência das máquinas filetadoras ou da destreza manual do operário, depende de algumas características intrínsecas à matéria-prima, ou seja, da forma anatômica do corpo, do tamanho da cabeça e do peso dos resíduos - vísceras, pele e nadadeiras (Contreras-Guzmán, 1994). Com isso, o rendimento no processamento pode variar entre espécies, dentro da mesma espécie e, ainda, de acordo com o peso de abate.

De acordo com Freato (2005), a determinação do rendimento do processamento de uma espécie e

Recebido em 16 de março de 2011

Aceito em 13 de julho de 2011

*Autor para correspondência (corresponding author)

E-mail: zoo@ucdb.br de suas relações com o peso de abate permite caracterizar o produto final e avaliar o seu potencial para a industrialização, bem como estabelecer o peso ideal de abate e as equações de predição do rendimento da carcaça e do filé. A forma externa do corpo do peixe tem grande importância na escolha do processamento realizado pela indústria, pois influencia nas operações de decapitação, evisceração e limpeza geral, que podem ser por métodos manuais ou mecanizados, no dimensionamento das caixas, de câmaras e de outros implementos para a armazenagem, na adequação e no rendimento da carne quando pré-processada na forma de corpo limpo, postas e filés, e na velocidade de resfriamento e de congelamento na indústria (Contreras-Guzmán, 1994).

Assim, o objetivo deste trabalho foi avaliar o efeito da classe de peso ao abate sobre o rendimento do processamento do pacu.

Foi avaliado o rendimento de 96 peixes, tratados em viveiro-terra com ração comercial. Ao final do período de cultivo e após 24 horas de jejum, os peixes foram despescados aleatoriamente, insensibilizados por choque térmico, por meio do contato com solução água-gelo, e abatidos por anóxia. Após o abate foram pesados e separados em classes - classe I formada com peixes de 135 a 285g; classe II com peixes de 310 a 385g; classe III com peixes de 400 a 585g; classe IV com peixes de 600 a $1.285 \mathrm{~g}$ - e dissecados para obtenção do rendimento no processamento - 
porcentagem da cabeça (\%CAB), porcentagem das vísceras (\%VIS), rendimento do tronco limpo (RTL) e rendimento do filé (RF).
$\mathrm{Na}$ Tab. 1, encontram-se as médias do rendimento no processamento em cada classe de peso.

Tabela 1. Valores médios de rendimento de tronco limpo (RTL), rendimento de filé (RF), porcentagem de vísceras (\%VIS) e porcentagem de cabeça (\%CAB) do pacu (Piaractus mesopotamicus) segundo a classe de peso ao abate

\begin{tabular}{lcccc} 
& $\begin{array}{c}\text { Classe I } \\
(135 \mathrm{~g} \text { a 285g) }\end{array}$ & $\begin{array}{c}\text { Classe II } \\
(310 \mathrm{~g} \text { a 385g })\end{array}$ & $\begin{array}{c}\text { Classe III } \\
(400 \mathrm{~g} \text { a 585g })\end{array}$ & $\begin{array}{c}\text { Classe IV } \\
(600 \mathrm{~g} \text { a 1285g) }\end{array}$ \\
\hline RTL & $87,30 \mathrm{a}$ & $86,73 \mathrm{a}$ & $85,50 \mathrm{~b}$ & $84,55 \mathrm{~b}$ \\
RF & $28,50 \mathrm{c}$ & $30,11 \mathrm{~b}$ & $30,74 \mathrm{~b}$ & $32,65 \mathrm{a}$ \\
VIS & $12,70 \mathrm{~b}$ & $13,27 \mathrm{~b}$ & $14,51 \mathrm{a}$ & $15,45 \mathrm{a}$ \\
CAB & $20,49 \mathrm{a}$ & $18,10 \mathrm{a}$ & $16,60 \mathrm{~b}$ & $16,39 \mathrm{~b}$ \\
\hline
\end{tabular}

Médias seguidas de letras distintas na linha diferem entre si pelo teste Tukey a 5\% de significância.

Os resultados do teste de médias revelaram que houve efeito $(\mathrm{P}<0,05)$ da classe de peso ao abate sobre as variáveis analisadas. O rendimento do RTL, ou seja, carcaça sem a presença da cabeça, nadadeiras, vísceras e pele, foi maior nas classes de peixes de menor peso. Para o RF, o maior valor observado foi na classe IV, a de peixes de maior peso. A \%VIS aumentou com o aumento de peso dos peixes, isto é, foi menor nas classes de peso I e II, e maior nas classes de peso III e IV $(\mathrm{P}<0,05)$. Para \%CAB, observou-se diminuição de acordo com o aumento de peso do peixe, sendo observados valores mais altos nas classes de peso I e II, e menores nas de peso III e IV.

O RTL para o pacu, mesmo na classe de maior peso, que apresentou rendimento de $84,6 \%$, foi mais alto que os observados em algumas espécies de peixes cultiváveis, como a tilápia-donilo (Oreochromis niloticus), com 51,4\% (Santos, 2004), surubim (Pseudoplatystoma fasciatum), com 75,3\% (Ribeiro e Miranda, 1997), matrinxã (Brycon cephalus), com 70,2\% (Vilas Boas, 2001), e mostrou-se próximo aos verificados para piracanjuba (Brycon orbignyanus), com 79,4\% (Freato, 2005).

Reis Neto (2007), ao avaliar a morfologia de pacus e de seu híbrido tambacu, relatou valores de rendimento de carcaça de 72,8 e 80,3\%, respectivamente, próximos aos rendimentos encontrados no presente estudo.
O rendimento do filé aumentou conforme aumentou a classe de peso dos peixes, estando próximo ao rendimento de filé encontrado em tilápia-do-nilo, com 32\% (Santos, 2004), e mais baixo que o rendimento de filé do bagre-do-canal (Ictalurus puntactus), com 39,5\% (Marengoni et al., 1998), e da piracanjuba, 44,2\% (Freato, 2005). Segundo Contreras-Gusmán (1994), essa diferença de rendimento de filés deve-se à superioridade do rendimento das partes comestíveis em peixes fusiformes, em relação aos peixes compridos.

A \%VIS aumentou em função do aumento da classe de peso, até atingir o máximo de 15,4\%, em peixes com peso médio de abate de $850 \mathrm{~g}$. Esse aumento deve-se, provavelmente, à proximidade da maturidade sexual, uma vez que foi considerado como víscera todo o conteúdo da cavidade celomática, incluindo as gônadas e a gordura celomática.

Diante dos resultados, sugere-se que peixes destinados ao processo de filetagem devem ser abatidos, preferencialmente, com pesos mais elevados, e que os peixes a serem comercializados na forma de carcaça ou inteiros eviscerados podem ser abatidos com pesos menores.

Palavras-chave: peixe, carcaça, filé 


\begin{abstract}
The objective was to evaluate the effect of slaughter weight on the processing efficiency of Pacu (Piaractus mesopotamicus).The fish were cultivated in a soil vivarium and fed commercial feed. After ten months of cultivation, 96 fish were deadened, slaughtered, weighed and dissected to determine the yield of clean body, fillet and percentage of entrails. The weight classes analyzed were: CI - 135 to 285g; CII 310 to 385g; CIII - 400 to 585g; CIV - 600 to 1.285g. For the variance analysis the data was grouped in four weight classes, and the regression equations were estimated regarding mean weight in each class. No effect of the weight class $(P>0,05)$ was observed on the yield of clean body (RTL). However, there was a linear effect $(P<0,05)$ of the weight classes in slaughter over the fillet yield $(R F)$ and percentage of entrails. Pacus slaughtered in more elevated weight classes had greater filled yield. Thus, the fish destined to the fillet process should preferably be slaughtered at higher weights. The fish cultivated with the objective of being commercialized as a carcass or whole with entrails removed may be slaughtered at lower weights.
\end{abstract}

Keywords: fish, carcass yield, fillet yield

\section{REFERÊNCIAS BIBLIOGRÁFICAS}

CARVALHO, R.; LEMOS, R. Aquicultura e consumo de carnes no Brasil e no mundo. Panor. Aquic., v.19, p.15-23, 2009.

CONTRERAS-GUZMÁN, E.S. Bioquímica de pescados e derivados. 1.ed. Jaboticabal: FUNEP, 1994. 409 p.

FREATO, T.A. Efeito do peso ao abate nos rendimentos do processamento da Pirancanjuba (Brycon orbignyanus), Valenciennes, 1849). 2005. 90f. Dissertação (Mestrado em Zootecnia) Universidade Federal de Lavras, Lavras, MG

MARENGONI, N.G.; SOUZA, M.R.; CAÇADOR, W.C. Rendimento de filetagem de bagre africano (Clarias gariepinu) e bagre americano (Ictalurus punctatus). In: REUNIÃO ESPECIAL DA SOCIEDADE BRASILEIRA PARA O PROGRESSO DA CIÊNCIA, 1998, Maringá. Anais... Maringá: Sociedade Brasileira para o Progresso da Ciência, 1998. p.523-524.

REIS NETO, R.V. Avaliações morfométricas de juvenis de pacu (Piaractus mesopotamicus) e tambaqui (Colossoma macropomum) e seus híbridos. 2007. 74f. Dissertação (Mestrado em Zootecnia) - Universidade Federal de Lavras, Lavras, MG.
RIBEIRO, L.P.; MIRANDA, M.O. Rendimento de processamento do surubim (Pseudoplatystoma fasciatum). Belo Horizonte, MG: IBAMA, p.29-35, 1997.

SANTOS, V.B. Crescimento morfométrico $e$ alométrico de linhagens de tilápia (Oreochromis niloticus). 2004. 86f. Dissertação (Mestrado em Zootecnia) - Universidade Federal de Lavras, Lavras, MG.

VAZ, M.M.; TORQUATO, V.C.; BARBOSA, N.D.C. Guia ilustrado de peixes da bacia do Rio Grande. 1.ed. Belo Horizonte: CEMIG/CETEC, 2000. 144 p.

VILAS BOAS, G.C. Morfometria, rendimento do processamento e composição química do filé de matrinxã (Brycon cephaly). 2001. 56f. Dissertação (Mestrado em Zootecnia) - Universidade Federal de Lavras, Lavras, MG. 